Mild Hypertension: Natural History and Management

Edited by F. Gross and T. Strasser. Proceedings of the Joint WHO/ISH meeting held in Susono, Japan. Pp. $x+337$, illustrated. Pitman Medical, London, 1979. $£ 10.00$.

A major world-wide effort is under way to provide guidelines and establish criteria for the correct management of mild hypertension. Those who read this book hoping it will provide the answers will be disappointed. What they will find, however, is an up-to-date discussion of the current state of play and the major outstanding issues.

Leading authorities present some 30 papers under the headings of Natural History, the Vascular System, Influencing Factors, progress reports on Trials, and General Management. Each paper has references, generally relevant and up-to-date, and an editor's summary, and is followed by discussion.

Whilst we are learning so much about populations great and small the management of individuals comes down to the root problem of determining a person's blood pressure and his particular risk of complications.

However, a fuller understanding of the population aspects can only be of benefit to the practising clinician. This book is warmly recommended on these grounds. The editors and publishers are to be especially congratulated on the speed with which the symposium has been translated into print.

\section{Pathogenic Streptococci}

Proceedings of the VIIth International Symposium on Streptococci and Streptococcal Diseases held in Sept. 1978.

Edited by M. T. PARKer. Pp. 296, illustrated. Reedbooks, Chertsey, Surrey, 1979. £21.00.

Despite the decline of Streptococcus pyogenes from its preeminent position as a leading cause of mortality and morbidity-especially in hospital, this organism, joined by group B streptococci and other relatives, remains a very important human pathogen. The continued and enthusiastic interest of research workers in the streptococcal field is very evident from the impressive collection of symposium papers under review.

With commendable speed, 156 short but varied papers have been assembled under the editorship of Dr Parker. Concise, up-to-date accounts are given of the structural, immunological and other clinically relevant features of these organisms. While the volume will, of course, be of most interest to microbiologists, a much wider medical audience will find many items of value scattered through its pages. The book is recommended for purchase by medical libraries, although the price will alarm librarians and their committees.

\section{Principles of Immunology}

Edited by N. R. Rose, F. Milgrom and C. J. Van Oss. Second edn. Pp. xiv +544 , illustrated. Bailliere Tindall, London, New York, MacMillan, 1979. £9.50.

There are few areas of medicine which have not been touched by immunology, and thus most clinicians would like to feel that they had a grasp of its basic principles. The editors of this book have set out both to keep the non-specialist abreast of current developments, and to lead the uninitiated to an understanding of the subject. Immunology is a great integrator: it brings together the physician, biochemist, microbiologist, cell biologist, geneticist, and members of many other discplines. Communication between the laboratory research scientist and the physician is essential, on the one hand to increase the relevance of basic research, and on the other to increase the health practitioner's awareness of the broader implications of the advances made. This book bridges the gap by a division into 2 major sections. The first covers basic concepts in immunology from the origins of the immune response as a means for the recognition of 'non-self' to the details of how the specificity of lymphocyte sensitization and antibody production have been achieved. Sections on the anatomy of the immune system move on to the biochemical basis of antigen and antibody interactions, and the cellular and humoral mechanisms of immunity and their control. The second half of the book, concerned with clinical immunology, examines the response to infection, the concept of hypersensitivity reactions and resultant tissue damage, immunodeficiency disorders, and tumour and transplant immunology. In the final section, the practical applications of immunological techniques in diagnosis and therapy are discussed. Clearly the editors have set their contributors a monumental task. The chapters are graduated in complexity, so that systematic reading would allow one to build up a working knowledge of the subject. Individual chapters form self-contained reviews, with a brief bibliography. There is extensive and effective cross-referencing in case the reader finds himself out of his depth. There is a useful index.

This is not a book for the busy clinician looking for the possible immunological features of specific diseases. Ulcerative colitis, coeliac disease, and even allergy do not feature as such in the index. All are discussed in the text, but in the context of auto-immune diseases or hypersensitivity disorders. This is a book about the science of immunology, it is lucid and readable. It would be a good introduction for the student of medicine and other biomedical sciences. It would be a useful reference source to the postgraduate, facing the constant flow of immunological terminology which so rapidly passes from the laboratory into daily clinical use.

\section{Principles and Practice of Dermatology}

By W. E. De Launey and W. A. Land. Pp. ix + 294, illustrated. Butterworths, Sydney, Melbourne, Brisbane, Adelaide, Perth, 1978. $£ 15.00$.

By and large, this is a competent, adequate orthodox, and fairly up-to-date review of most of the diseases one is likely to meet in general dermatological practice. The reviewer's grumbles concern matters of detail only. The text is fairly unimaginative, but definitely practical and sound, and follows the standard pattern of other similar sized books published in recent decades. It is clinically, rather than scientifically, orientated but that does not imply adverse criticism except to say that as there are a mere 8 colour plates, which are of just about adequate quality although rather small, one feels that an inexpensive skin atlas might be needed in conjunction with this book.

This book could suit the M.R.C.P, candidate, and would be a useful introduction for the dermatologist in the first few months of his training. Perhaps the former would prefer to spend his $£ 15$ elsewhere, and the latter might wish to save his money and put it towards a standard and more costly text, such as 'Rook'.

\section{The Treatment of Obesity}

The Current Status of Modern Therapy. Vol. 2. Edited by J. F. Munro. Pp. xi +234 , illustrated. MTP Press, Lancaster, 1979. $£ 12.95$.

This is a 234 page exhaustive treatise on all aspects of obesity - how to treat, when to treat, diets, clinical pharmacology (including the anorexic drugs), exercise, starvation, bypass surgery, psychotherapy and Weight Watchers. There are 13 contributors from 4 different countries to provide an international viewpoint and a vast number of modern references. It is a valuable source book for those engaged in health programming, research on obesity, clinical pharmacologists and nutritionists. 